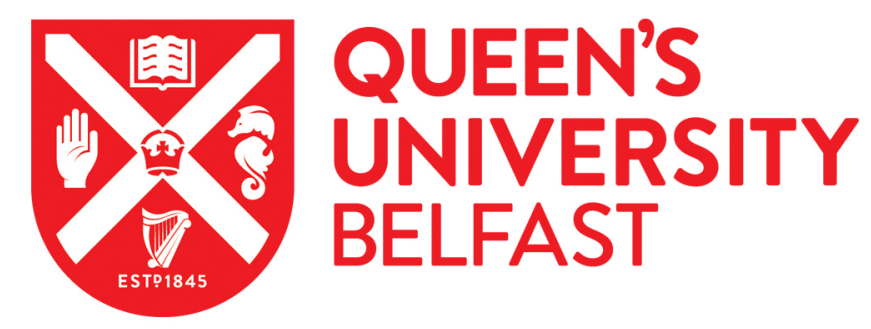

\title{
Retinal Vascular Caliber, Iris Color, and Age-Related Macular Degeneration in the Irish Nun Eye Study
}

\author{
McGowan, A., Silvestri, G., Moore, E., Silvestri, V., Patterson, C. C., Maxwell, A. P., \& McKay, G. J. (2015). \\ Retinal Vascular Caliber, Iris Color, and Age-Related Macular Degeneration in the Irish Nun Eye Study. \\ Investigative ophthalmology \& visual science, 56(1), 382-387. https://doi.org/10.1167/iovs.14-15523
}

\section{Published in:}

Investigative ophthalmology \& visual science

\section{Document Version:}

Peer reviewed version

\section{Queen's University Belfast - Research Portal:}

Link to publication record in Queen's University Belfast Research Portal

Publisher rights

Copyright 2015 The Association for Research in Vision and Ophthalmology, Inc.

\section{General rights}

Copyright for the publications made accessible via the Queen's University Belfast Research Portal is retained by the author(s) and / or other copyright owners and it is a condition of accessing these publications that users recognise and abide by the legal requirements associated with these rights.

Take down policy

The Research Portal is Queen's institutional repository that provides access to Queen's research output. Every effort has been made to ensure that content in the Research Portal does not infringe any person's rights, or applicable UK laws. If you discover content in the Research Portal that you believe breaches copyright or violates any law, please contact openaccess@qub.ac.uk. 
1 Retinal vascular caliber, iris color and age-related macular degeneration in the Irish

2 Nun Eye Study

3 Amy McGowan ${ }^{1}$, Giuliana Silvestri², Evelyn Moore ${ }^{3}$, Vittorio Silvestri ${ }^{3}$, Christopher C.

4 Patterson $^{1}$, Alexander P. Maxwell ${ }^{1}$, Gareth J. McKay ${ }^{1^{*}}$

$5 \quad{ }^{1}$ Centre for Public Health, Queen's University Belfast, Belfast, Northern Ireland

$6 \quad{ }^{2}$ Centre for Experimental Medicine, Queen's University Belfast, Belfast, Northern Ireland

$7 \quad{ }^{3}$ Department of Ophthalmology, Royal Victoria Hospital, Belfast, Northern Ireland

$9 \quad{ }^{*}$ Corresponding Author: Gareth J. McKay, ${ }^{1}$ Centre for Public Health, Queen's University Belfast, Belfast, Northern Ireland, BT12 6BA; g.j.mckay@qub.ac.uk

Financial Support: The project was funded by the Medical Research Council UK, grant number MR/K003364/1, Diabetes UK, grant number 11/0004400 and the Northern Ireland Health HPSS R\&D Office, Belfast, grant number RRG project 4.41. The funding organizations had no role in the design or conduct of this research.

\section{ABSTRACT (250 words)}

PURPOSE. To evaluate the relationship between retinal vascular caliber (RVC), iris color and age-related macular degeneration (AMD) in elderly Irish nuns.

METHODS. Data from 1233 participants in the cross-sectional observational Irish Nun Eye Study were assessed from digital photographs with a standardized protocol using computerassisted software. Macular images were graded according to the modified Wisconsin age- 
related maculopathy grading system. Regression models were used to assess associations, adjusting for age, mean arterial blood pressure, body mass index, refraction and fellow RVC.

RESULTS. In total, 1122 (91\%) participants had gradable retinal images of sufficient quality for vessel assessment (mean age: 76.3 years [range: 56-100 years]). In an unadjusted analysis, we found some support for a previous finding that individuals with blue iris color had narrower retinal venules compared to those with brown iris color $(P<0.05)$ but this was no longer significant after adjustment. AMD status was categorized as no AMD, any AMD and late AMD only. Individuals with any AMD (early or late AMD) had significantly narrower arterioles and venules compared to those with no AMD in an unadjusted analysis but this was no longer significant after adjustment. A non-significant reduced risk of any AMD or late AMD only was observed in association with brown compared to blue iris color, in both unadjusted and adjusted analyses.

CONCLUSIONS. RVC was not significantly associated with iris color or early/late AMD after adjustment for confounders. A lower but non-significant AMD risk was observed in those with brown compared to blue iris color. 


\section{Introduction}

In recent years, studies have shown that non-invasive measurement of retinal blood vessels may offer insights into certain systemic diseases ${ }^{1-8}$, highlighting the eye as a unique window to view microvascular health elsewhere within the body. This opportunity may afford clinicians and other health professionals mechanistic insight into diseases with a microvascular component ${ }^{5}$.

Previous studies have examined ethnic and racial variation in retinal microvascular characteristics, identifying an association between retinal vessel caliber (RVC) and ethnicity, principally on the basis of a darker iris colour ${ }^{9-12}$. The reason for the observed racial and ethnic differences in RVC is uncertain but several underlying factors have been proposed including genetic variation, anthropometric and ocular biometrics, varying susceptibility to vascular risk factors, or perhaps measurement error as a result of reduced vessel contrast against a more pigmented epithelium ${ }^{10}$. Furthermore, it has also been reported that individuals with a lighter iris color were more likely to have a higher prevalence and a greater likelihood of progression to late AMD than those with a darker iris color ${ }^{13}$.

Age-related macular degeneration (AMD; MIM\# 603075) is the most common form of visual impairment among older people of European descent ${ }^{14}$, accounting for more than half of all new cases of registered blindness ${ }^{15}$. Several epidemiological studies have suggested common mechanistic processes and risk factors shared between AMD and cardiovascular disease (CVD) ${ }^{16-18}$ and some have examined the relationship between RVC and AMD, although the findings reported have been inconsistent ${ }^{19-25}$. It has been suggested that changes in RVC may be a risk factor for AMD, and that factors involved in the pathogenesis of AMD such as inflammation may influence RVC at an earlier stage before AMD manifestations are observed clinically. As such, changes in RVC may potentially provide 
some prognostic indication for better risk stratification in individuals with an increased risk of developing AMD later in life.

As such, we sought to evaluate the relationship between RVC, iris color and AMD status using cross-sectional data from the Irish Nun Eye Study (INES) which included 1233 white participants aged 56-100 years.

\section{Methods}

\section{Study Population}

The INES was a cross-sectional observational study of eye health in white Irish nuns selected from convents across Ireland, with recruitment between 2007 and 2009. It was designed specifically to examine the prevalence of AMD in a population with a restricted lifestyle and also to examine the relationship between light exposure and AMD.

\section{Study characteristics}

Contact was made with 152 convents, of which 126 (82.9\%) responded and agreed to participate. One thousand, five hundred nuns in these 126 convents were invited to take part in the study and 1233 (82.2\%) agreed. Those who did not participate tended to be ill or unavailable on the day of examination. The inclusion criteria mandated participants to be of Irish descent, aged over 55 years and have lived in a convent for at least 25 years. There were no specific exclusion criteria. In order to maximise recruitment and minimise disruption to participant routines, all examinations were carried out within the community. The study was approved by the Institutional Review Board and the Office for Research Ethics Committee Northern Ireland and adhered to the tenets of the Declaration of Helsinki. Informed written consent was obtained from all participants prior to participation. 


\section{Demographic Data}

Demographic data were obtained from interviews by a trained field worker using a structured questionnaire. This study was specific to one ethnicity as only white Irish nuns were included.

\section{Anthropometric and Blood Pressure Measurements}

Blood pressure was measured in a seated position with an oscillometric blood pressure aneroid sphygmomanometer (Speider and Keller) after the questionnaires had been completed. Mean arterial blood pressure (MABP) was calculated as one third of the systolic (SBP) plus two thirds of the diastolic blood pressure (DBP). Height, weight, and waist circumference were measured and body mass index (BMI) calculated as weight (in kilograms) divided by height (in meters) squared.

\section{Ocular Examination and Retinal Photography.}

Each individual underwent a comprehensive ophthalmic examination. Medical and ophthalmic questionnaires covered areas such as medical and ocular history and relevant risk factors for AMD. Iris color was determined from the undilated pupil of each eye by a single examiner (EM) and categorized by comparison with four standard photographs prior to pupil dilation as blue, brown, hazel or green. Refractive error was recorded either from a recent prescription or from the participant's glasses. Where glasses were not available, corrected visual acuity was achieved by pinhole correction: refraction was not carried out. Each individual had anterior segment photography, photography of the skin around the eyes and forehead and retinal findings were recorded by stereoscopic retinal imaging using the NIDEX AFC 210 digital camera. Fields 1 and 2 were captured following dilation of the pupils with $1 \%$ tropicamide.

\section{AMD Characterization}


All images were independently graded by the Network of Ophthalmic Reading Centres UK (NetwORC UK) in Belfast. Anonymized images were submitted to NetwORC UK and trained graders followed a standardized procedure to identify the characteristics of early and late AMD using the definitions of the Wisconsin Age Related Maculopathy Grading System ${ }^{26}$. The definitions for AMD were based on the International Classification for Age-related Macular Degeneration ${ }^{27}$. The presence of features within a $6000 \mu \mathrm{m}$ circle centered on the fovea was recorded. Drusen were classified according to size, characteristics of homogeneity of surface features and outline. Pigmentary changes were classified into two categories; hyperpigmentation and hypopigmentation. These features were used to assign each eye to a severity grade as follows: No AMD: no features of AMD or the presence of soft distinct drusen ( $>63 \mu \mathrm{m}$ and $\leq 125 \mu \mathrm{m})$ or pigmentary abnormalities only; early AMD: soft, indistinct $(\geq 125 \mu \mathrm{m})$ or reticular drusen only or soft distinct drusen with pigmentary abnormalities; late AMD: either geographic atrophy; (well demarcated area of retinal pigment atrophy with visible choroidal vessels) or neovascular AMD (presence of any of the following): serous or hemorrhagic retinal or retinal pigment epithelial detachment, subretinal neovascular membrane, or periretinal fibrous scar.

\section{Retinal vessel caliber assessment}

Retinal arteriolar and venular calibers were measured using Interactive Vessel ANalysis software (IVAN; University of Wisconsin, Madison, WI) according to a standardized protocol for all retinal vessels located between a half and one disc diameter distance from the optic disc margin in the digitized image. The revised Knudston-Hubbard formula ${ }^{28}$, was used to summarize these measurements as CRAE (Central Retinal Arteriolar Equivalent) and CRVE (Central Retinal Venular Equivalent), which represents the average caliber of the arterioles and venules in each examined eye. A single trained grader (AMG), blinded to the participants' characteristics, conducted all retinal measurements. Reproducibility of retinal 
vascular measurements was high with intragrader reliability assessed in 200 randomly selected retinal photographs and an intraclass correlation coefficient (95\% confidence interval) calculated as $0.975(0.967-0.981)$ for CRAE and 0.993 (0.990 - 0.994) for CRVE, respectively. A high correlation between the right and left eyes in retinal vascular measurements has been reported elsewhere ${ }^{28}$. Data from the right eye was used and when unavailable, was replaced by the left eye.

\section{Statistical Analysis}

All statistical analyses were performed using IBM SPSS Statistics version 21 (IBM Corp., Armonk, NY). Quantitative retinal vascular caliber was assessed as a continuous variable. One-way analysis of variance and multiple linear regression analyses were used to compare the mean CRAE and CRVE by iris color in both unadjusted (Model 1) and adjusted analyses (Models 2, 3 and 4). The minimally adjusted model (Model 2) included covariates for refraction, age, BMI, and MABP. The model was not adjusted for gender as all participants were female. The fully adjusted model (Model 4) also included the covariates from the minimally adjusted model in addition to diabetes mellitus status, hypertension, ever smoker, ischemic heart disease (IHD), cerebrovascular accident (CVA), alcohol consumption (yes/no) and the fellow vessel (venule or arteriole) caliber (i.e. CRAE as a covariate in the analysis of CRVE and vice versa) as suggested previously ${ }^{29}$. The same approach was used to compare CRAE and CRVE according to AMD status with adjustment for potential confounders in a minimally and fully adjusted model as described for iris color. Logistic regression was used to assess the significance of iris color as a predictor of AMD status. Separate analyses of any AMD (early and late AMD) versus no AMD and of late AMD only versus no AMD were performed each with adjustment for confounders. A P value $<0.05$ was regarded as statistically significant. 


\section{Results}

161 In total, gradable retinal images of sufficient quality for vessel assessment were available in $1621122(91 \%)$ of the 1233 participants. Images were not available for 111 participants, in part 163 as a consequence of difficulties with image acquisition due to postural complications with 164 the elderly participant, poor pupillary dilation, the presence of an artificial eye or an out of 165 focus image. Participants with missing retinal vessel caliber measurements $(n=111)$ were 166 significantly older and more likely to have moderate to severe cataract than those with retinal 167 images captured ( $P<0.001 ; 84.8$ years vs 76.3 years; Table 1$) ; 11$ had no retinal images 168 captured and 60 had macula-centered images only, which were not amenable to 169 measurement using the IVAN software. The mean age of the 1122 participants included 170 was 76.3 years (range: $56-100$ years). 
172 Table 1. Summary statistics of participants.

\begin{tabular}{|c|c|c|c|c|}
\hline Characteristic & All participants & $\begin{array}{l}\text { Gradable } \\
(n=1122)\end{array}$ & $\begin{array}{l}\text { Ungradable } \\
(n=111)\end{array}$ & $\mathrm{P}$ \\
\hline Mean Age (SD, years) & $77.1(8.4)$ & $76.3(8.1)$ & $84.8(7.4)$ & $<0.001$ \\
\hline Mean BMI (SD, $\left.\mathrm{kg} / \mathrm{m}^{2}\right)$ & $24.5(5.1)$ & $24.6(5.1)$ & $23.8(5.0)$ & 0.09 \\
\hline Mean MABP (SD, mmHg) & $92.5(10.6)$ & $92.4(10.4)$ & $93.2(12.3)$ & 0.47 \\
\hline IHD n(\%) & $137(11 \%)$ & $120(11 \%)$ & $17(15 \%)$ & 0.20 \\
\hline CVA n(\%) & $40(3 \%)$ & $36(3 \%)$ & $4(3 \%)$ & 0.79 \\
\hline Ever Smoked n(\%) & $57(5 \%)$ & $49(4 \%)$ & $8(7 \%)$ & 0.22 \\
\hline Diabetes n(\%) & $37(3 \%)$ & $34(3 \%)$ & $3(3 \%)$ & 1.00 \\
\hline Hypertension n(\%) & $504(41 \%)$ & $454(40 \%)$ & $50(43 \%)$ & 0.59 \\
\hline Chronic Kidney disease & $705(60 \%)$ & $623(59 \%)$ & $82(74 \%)$ & 0.004 \\
\hline Alcohol consumption & $81(7.9 \%)$ & $77(8.2 \%)$ & $4(3.6 \%)$ & 0.20 \\
\hline 1-7 measures/week & $78(7.6 \%)$ & $74(7.9 \%)$ & $4(3.6 \%)$ & \\
\hline$>7$ measures/week & $3(0.3 \%)$ & $3(0.3 \%)$ & $0(0 \%)$ & \\
\hline Osteoporosis & $402(33 \%)$ & $365(33 \%)$ & 37 (31\%) & 0.78 \\
\hline *Statins & $482(39 \%)$ & $448(40 \%)$ & $34(28 \%)$ & 0.01 \\
\hline *Asprin & $420(34 \%)$ & $369(33 \%)$ & $51(42 \%)$ & 0.03 \\
\hline *Diuretics & $281(23 \%)$ & $240(21 \%)$ & $41(34 \%)$ & 0.001 \\
\hline *Beta Blockers & $215(17 \%)$ & $192(17 \%)$ & $23(19 \%)$ & 0.57 \\
\hline *Calcium channel blockers & $169(14 \%)$ & $142(13 \%)$ & $27(22 \%)$ & 0.003 \\
\hline *Ace inhibitors & $145(12 \%)$ & $134(12 \%)$ & $11(9 \%)$ & 0.37 \\
\hline${ }^{*}$ Corticosteroids & $66(5 \%)$ & $62(5 \%)$ & $4(3 \%)$ & 0.31 \\
\hline *NSAIDs & $62(5 \%)$ & $53(5 \%)$ & $9(7 \%)$ & 0.18 \\
\hline
\end{tabular}


173 SD: standard deviation; BMI: body mass index; MABP: mean arterial blood pressure (one 174 third of the systolic blood pressure plus two thirds of the diastolic blood pressure); IHD: 175 ischemic heart disease; CVA: cerebrovascular accident; NSAIDs: non-steroidal anti176 inflammatory drugs; *Medications with a frequency $>5 \%$.

\section{Iris color and retinal vessel caliber}

178 Iris color was characterized as blue (59.0\%), brown (20.2\%), hazel (14.4\%) and green

179 (6.5\%). CRAE and CRVE were normally distributed, with means and standard deviations 180 (SD) of 120.4 (12.6) $\mu \mathrm{m}$ and 169.0 (18.3) $\mu \mathrm{m}$ respectively. Table 2 shows the diameters $181(\mu \mathrm{m})$ for retinal vessel caliber categorised by iris color. Initial one-way analysis of variance 182 showed no significant differences in mean CRAE $(P=0.34)$ and CRVE $(P=0.15)$ between the 183 iris color groups.

184 Table 2. Summary retinal vessel caliber measurements: CRAE and CRVE by iris color.

\begin{tabular}{|c|c|c|c|c|}
\hline & Color & $\mathrm{N}$ & Mean $(\mu \mathrm{m})$ & SD \\
\hline \multirow[t]{4}{*}{ Central Retinal Arteriolar Caliber (CRAE) } & Blue & 662 & 120.0 & 12.5 \\
\hline & Brown & 227 & 121.6 & 12.7 \\
\hline & Hazel & 161 & 119.6 & 12.8 \\
\hline & Green & 72 & 121.1 & 12.4 \\
\hline \multirow[t]{4}{*}{ Central Retinal Venular Caliber (CRVE) } & Blue & 662 & 168.0 & 18.3 \\
\hline & Brown & 227 & 170.8 & 18.1 \\
\hline & Hazel & 161 & 169.3 & 18.2 \\
\hline & Green & 72 & 171.3 & 19.1 \\
\hline
\end{tabular}


186

187

Although an unadjusted analysis, suggested that individuals with brown iris color had significantly broader retinal venules $(P=0.05)$ compared to those with blue iris color (Table 3), this finding was not corrected for multiple comparisons. Iris color was no longer significantly associated with vascular caliber following adjustment for refraction, age, BMI, and MABP (Model 2), and additional covariates diabetes mellitus, hypertension, ever smoker, IHD, CVA, alcohol consumption (yes/no) and fellow vessel (Models 3 and 4),. All comparisons for arterioles were non-significant.

\section{AMD status and retinal vessel caliber}

AMD status was categorized as no AMD ( $n=975)$, early AMD ( $n=99)$ and late AMD ( $n=27)$. The summary statistics for those with any AMD and those without AMD are displayed in Table 4. In an unadjusted analysis, individuals with any AMD had significantly narrower CRAE $(P<0.05)$ and CRVE $(P=0.03)$ compared to those without AMD. Following adjustment for refraction, age, BMI, MABP (minimally adjusted, Model 2), and also for additional covariates (Models 3 and 4), AMD status was no longer significantly associated with vessel caliber (Table 5). 
Table 3. Difference in mean retinal vessel caliber $(\mu \mathrm{m})$ for each iris color compared to blue (reference group) in unadjusted (Model 1 ), minimally adjusted (Model 2) and fully adjusted (Models 3 and 4) analyses.

\begin{tabular}{lcccccccc}
\hline & Model 1 $(95 \% \mathrm{Cl})$ & $\mathrm{P}$ & Model 2 $(95 \% \mathrm{Cl})$ & $\mathrm{P}$ & Model 3 $(95 \% \mathrm{Cl})$ & $\mathrm{P}$ & Model $4(95 \% \mathrm{Cl})$ \\
\hline CRAE & & & & & & \\
Brown & $1.6(-0.4,3.5)$ & 0.11 & $1.2(-0.6,3.0)$ & 0.19 & $0.8(-1.2,2.8)$ & 0.46 & $-0.1(-1.6,1.5)$ & 0.92 \\
Hazel & $-0.4(-2.6,1.8)$ & 0.72 & $0.2(-1.9,2.3)$ & 0.84 & $-0.9(-3.2,1.4)$ & 0.44 & $-1.0(-2.8,0.7)$ & 0.25 \\
Green & $1.1(-2.0,4.1)$ & 0.49 & $-0.3(-3.2,2.6)$ & 0.83 & $-1.1(-4.2,2.1)$ & 0.50 & $-1.4(-3.8,1.0)$ & 0.26 \\
CRVE & & & & & & & & \\
Brown & $2.8(0.1,5.6)$ & 0.05 & $2.3(-0.3,4.9)$ & 0.09 & $2.0(-1.0,4.9)$ & 0.19 & $1.3(-1.0,3.5)$ \\
Hazel & $1.3(-1.8,4.5)$ & 0.41 & $1.8(-1.2,4.8)$ & 0.25 & $0.3(-3.0,3.7)$ & 0.85 & $1.2(-1.4,3.8)$ \\
Green & $3.3(-1.1,7.8)$ & 0.14 & $1.4(-2.8,5.6)$ & 0.53 & $0.8(-3.8,5.3)$ & 0.75 & $1.7(-1.8,5.3)$ \\
\hline
\end{tabular}

204 Model 2 - adjusted for refraction, age, BMI, and MABP

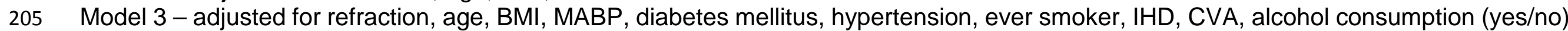

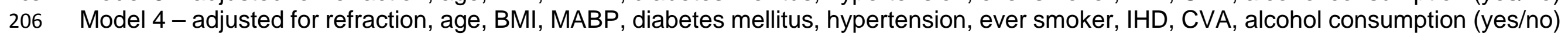
207 and fellow vessel caliber pressure; IHD: ischemic heart disease; CVA: cerebrovascular accident; 95\% Cl: 95\% confidence interval. 
211 Table 4. Summary statistics of participants included for retinal vessel assessment by AMD 212 status.

\begin{tabular}{|c|c|c|c|}
\hline Characteristic & $\begin{array}{c}\text { No AMD }(\mathrm{n}=976) \\
\text { mean }(\mathrm{SD})\end{array}$ & $\begin{array}{c}\text { Any AMD (n= } \\
126) \\
\text { mean (SD) }\end{array}$ & $P$ \\
\hline Mean Age (SD, years) & $75.6(8.0)$ & $81.3(6.7)$ & $<0.001$ \\
\hline Mean BMI(SD, kg/m²) & $24.7(5.1)$ & $24.5(4.8)$ & 0.70 \\
\hline $\begin{array}{l}\text { Mean MABP (SD, } \\
\mathrm{mmHg})\end{array}$ & $92.1(10.3)$ & $94.5(10.9)$ & 0.02 \\
\hline IHD n(\%) & $99(10 \%)$ & $14(11 \%)$ & 0.74 \\
\hline CVA n(\%) & $28(3 \%)$ & $7(6 \%)$ & 0.11 \\
\hline Ever Smoked n(\%) & $42(4 \%)$ & $7(6 \%)$ & 0.53 \\
\hline Diabetes n(\%) & $28(3 \%)$ & $6(5 \%)$ & 0.27 \\
\hline Hypertension n(\%) & $390(40 \%)$ & $57(45 \%)$ & 0.26 \\
\hline
\end{tabular}

213 Any AMD is composed of early and late AMD. SD: standard deviation; BMI: body mass 214 index; MABP: mean arterial blood pressure; IHD: ischemic heart disease; CVA: 215 cerebrovascular accident.

216 AMD status and iris color

217 Although a decrease in risk for any AMD was observed in association with brown compared 218 to blue iris color, this was not significant in both an unadjusted analysis $(\mathrm{OR}=0.73$; C.I.: 219 0.44-1.20; $\mathrm{P}=0.22$ ) and also in an analysis adjusted for age, BMI, MABP and refraction (OR $220=0.74 ;$ C.I.: 0.44-1.24; $P=0.25)$. Similarly, a decrease in risk for late AMD only was observed 221 in association with brown compared to blue iris color but again this was not significant in 222 both an unadjusted analysis ( $\mathrm{OR}=0.35 ; \mathrm{C} . \mathrm{I} .: 0.20-1.77 ; \mathrm{P}=0.35)$ and an analysis adjusted 223 for age, BMI, MABP and refraction (OR = 0.61; C.I.: 0.20-1.86; $P=0.39)$. 


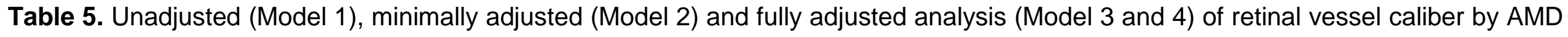
status (any AMD versus no AMD).

\begin{tabular}{|c|c|c|c|c|c|c|c|c|}
\hline & Model $1(95 \% \mathrm{Cl})$ & $\mathrm{P}$ & Model $2(95 \% \mathrm{Cl})$ & $\mathrm{P}$ & Model $3(95 \% \mathrm{Cl})$ & $\mathrm{P}$ & Model $4(95 \% \mathrm{Cl})$ & $\mathrm{P}$ \\
\hline CRAE & $-3.8(-6.8,-1.5)$ & 0.001 & $-1.3(-3.6,1.0)$ & 0.27 & $-2.0(-4.5,0.6)$ & 0.13 & $-1.9(-3.9,0.1)$ & 0.06 \\
\hline CRVE & $-3.7(-7.0,-0.3)$ & 0.03 & $0.1(-3.3,3.4)$ & 0.98 & $-0.3(-3.9,3.4)$ & 0.88 & $1.5(-1.4,4.4)$ & 0.30 \\
\hline
\end{tabular}

\section{Model 1 - unadjusted}

Model 2 - adjusted for refraction, age, BMI, MABP and iris color

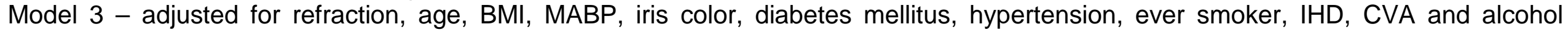
consumption (yes/no)

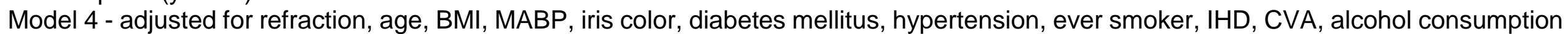
(yes/no) and fellow vessel caliber

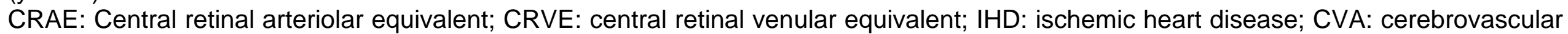
accident; 95\% Cl: 95\% confidence intervals. 


\section{Discussion}

236

237

238

In this study, we did not find a significant association between retinal vessel caliber and iris color in our study population of white Irish nuns. The Sydney Childhood Eye Study ${ }^{10}$ (SCES) reported that both CRAE and CRVE were significantly wider in children of East Asian ethnicity compared with white children and that white children with darker iris colour had both wider CRAE and CRVE. Rochtchina and colleagues hypothesized that the ethnic variability observed in association with retinal vessel caliber, may have contributed to measurement error as a consequence of contrast sensitivity associated with the software's ability to delineate the vessel edges against the background retinal pigment epithelium and its associated level of pigmentation (iris color as a proxy for skin pigmentation). If true, this could result in an over estimation of vessel caliber as the software finds it more difficult to delineate the true blood vessel edges.

The association between RVC and ethnicity is well established with the Multi-ethnic Study of Atherosclerosis ${ }^{12}$ (MESA) concluding that blacks and Hispanics had wider CRAE and CRVE than whites and Chinese. Similarly, the Singapore Childhood Study of Risk Factors for Myopia ${ }^{11}$ (SCORM) demonstrated that CRAE and CRVE were both significantly narrower in Chinese children compared to Malay and Indian children. The findings from SCORM suggested the underlying reasons for the variations between ethnic and racial groups observed were unclear but perhaps reflected differences and varying susceptibility to vascular risk factors such as blood pressure, anthropometric and ocular measures and/or genetics. More recently, the Multi-ethnic study of Healthy Asians ${ }^{9}$, reported that Indians had the widest CRAE and CRVE measurements, followed by the Malay and then the Chinese.

Our study is limited to white Irish nuns (females only), minimizing ethnicity as a potential confounder. Our findings do not indicate any significant association between RVC and iris color which in part adds support to previous suggestions that variation observed in RVC may 
260

be influenced by underlying ethnic differences, as opposed to iris color per se. Nevertheless, the possibility that iris color and/or retinal pigmentation levels may influence contrast sensitivity and the ability of the analysis software to delineate blood vessel edge, cannot be excluded.

We failed to find an association with AMD following adjustment for potential confounders and our findings support those from previous studies ${ }^{19-21,24,25}$, but contrast those from the Singapore Malay Eye Study ${ }^{22}$ and the Handan Eye Study ${ }^{23}$. The Handan Eye Study consisted of 199 individuals with early AMD and 400 age-matched controls (mean age 58.6), and reported a significant association between wider retinal arteriolar caliber and early AMD and soft distinct drusen. The Singapore Malay Eye Study comprised 3280 participants aged between 40 and 80 years (mean age 58.7 years), and reported a wider venular caliber associated with an increased prevalence of early AMD.

Within our study, it is important to consider the pathological pathways involved in AMD etiology, such as inflammation, which may influence the retinal microvasculature, although whether the retinal or choroidal circulation are more likely to influence the disease processes, requires further investigation ${ }^{25}$. Previous studies have implicated common mechanistic processes and risk factors shared between AMD and CVD with subsequent risk modification for both conditions by smoking, hypertension, inflammatory markers and common genetic variants, although consistent supporting evidence from cross-sectional studies has proved elusive, possibly as a consequence of potential confounding ${ }^{30-31}$. Studies examining the relationship between AMD and CVD risk factors have identified associations between higher pulse pressure, higher systolic blood pressure and increased carotid wall thickness and incident AMD, implicating a vascular re-modelling process ${ }^{32-33}$. Previous studies have also suggested that lighter iris color increases associated AMD risk, i.e. individuals with blue iris color were more inclined to have a higher prevalence and a 
stronger likelihood of progression to late AMD than those with a darker iris color ${ }^{13}$. We were unable to corroborate these findings in our study.

The strengths of this study include the relatively large sample size and the high proportion of gradable digital retinal images. Masked evaluation of RVC was performed by a single trained grader. The use of a semi-automated computer based technique ${ }^{34}$ to measure RVC. The collection of data on potential confounders including anthropometric factors was standardized and the relative uniformity of the nun's backgrounds meant fewer variations in lifestyle, reducing potential confounding and provided an opportunity to examine the potential complex relationship that exists between AMD and CVD risk factors, iris color and the resultant effect on RVC. Importantly, our study was performed on a well-characterized and aged cohort (mean age 76.3 years), free from gender or ethnicity related confounding, which is particularly important for the analysis of age-related conditions such as AMD. Due to the nature of their lifestyle, this novel population have lower rates of some well-recognized environmental and lifestyle related risk factors, i.e. the majority were non- smokers, had lower rates of alcohol consumption with reduced prevalence of cardiovascular disease and diabetes, providing an opportunity to better examine lifestyle and environmental factors that contribute to the etiology of complex diseases.

Limitations of our study include its cross-sectional design which did not let us determine whether changes observed precede or are a consequence of AMD. The data available to evaluate late AMD were relatively small in number, limiting the power to evaluate RVC in the advanced form of this condition. Furthermore, certain data which may affect RVC including. intraocular pressure ${ }^{35}$ was unavailable. While convent or religious orders may not truly reflect the general population, they nevertheless offer an excellent opportunity to study a well-characterized model of 'healthy ageing'. 
309 In conclusion, our cross-sectional study of aged white Irish Nuns, has not found a significant 310 association between retinal vascular caliber and iris color, between retinal vascular caliber 311 and $\mathrm{AMD}$ and between iris color and AMD, following adjustment for appropriate known 312 confounders. 


\section{References}

1. Ding J, Ikram MK, Cheung CY, Wong TY. Retinal vascular calibre as a predictor of incidence and progression of diabetic retinopathy. Clin Exp Optom. 2012;95(3):2906.

2. Sasongko $\mathrm{MB}$, Wong $\mathrm{TY}$, Donaghue $\mathrm{KC}$, et al. Retinal arteriolar tortuosity is associated with retinopathy and early kidney dysfunction in type 1 diabetes. Am J Ophthalmol. 2012;153(1):176-83.

3. Yau JWY, Xie J, Lamoureux E, et al. Retinal microvascular calibre and risk of incident diabetes: the multi-ethnic study of atherosclerosis. Diabetes Res Clin Pract. 2012;95(2):265-74.

4. Cheung CY, Ikram MK, Sabanayagam C, Wong TY. Retinal microvasculature as a model to study the manifestations of hypertension. Hypertension. 2012;60(5):10941103.

5. Wong TY. Retinal Vessel Diameter as a Clinical Predictor of Diabetic Retinopathy Progression: ime to take out the measuring tape. Arch Ophthalmol. 2011;129(1):9596.

6. Cheung N, Wong TY. Predicting Risk of Diabetic Retinopathy From Retinal Vessel Analysis; personalised medicine in transition. Arch Opthalmol. 2012;130(6):783-784.

7. Cheung CY, Tay WT, Ikram MK, et al. Retinal microvascular changes and risk of stroke: the Singapore Malay Eye Study. Stroke. 2013;44(9):2402-8.

8. Cheung $\mathrm{CY}$, Ong YT, Ikram MK, et al. Microvascular network alterations in the retina of patients with Alzheimer's disease. Alzheimers Dement. 2014;10(2):135-42. 
9. $\mathrm{Li} \mathrm{X}$, Wong WL, Cheung $\mathrm{CY}$, et al. Racial differences in retinal vessel geometric characteristics: a multiethnic study in healthy Asians. Invest Ophthalmol Vis Sci. 2013;54(5):3650-6.

10. Rochtchina E, Wang JJ, Taylor B, Wong TY, Mitchell P. Ethnic variability in retinal vessel caliber: a potential source of measurement error from ocular pigmentation?-the Sydney Childhood Eye Study. Invest Ophthalmol Vis Sci. 2008;49(4):1362-6.

11. Cheung N, Islam FMA, Saw SM, et al. Distribution and associations of retinal vascular caliber with ethnicity, gender, and birth parameters in young children. Invest Ophthalmol Vis Sci. 2007;48(3):1018-24.

12. Wong TY, Islam FMA, Klein R, et al. Retinal vascular caliber, cardiovascular risk factors, and inflammation: the multi-ethnic study of atherosclerosis (MESA). Invest Ophthalmol Vis Sci. 2006;47(6):2341-50.

13. Nicolas CM, Robman LD, Tikellis G, et al. Iris colour, ethnic origin and progression of age-related macular degeneration. Clin Experiment Ophthalmol. 2003;31(6):465-9.

14. Centers for Disease Control and Prevention (CDC). Prevalence of Visual Impairment and Selected Eye Diseases Among Persons Aged $\geq 50$ Years With and Without Diabetes - United States, 2002. MMWR Morb Mortal Wkly Rep. 2004;53:1069-71.

15. Bunce C, Xing W, Wormald R. Causes of blind and partial sight certifications in England and Wales: April 2007-March 2008. Eye (Lond). 2010;24(11):1692-9.

16. Snow KK, Seddon JM. Do age-related macular degeneration and cardiovascular disease share common antecedents? Ophthalmic Epidemiol. 1999;6(2):125-43. 
17. Wong TY, Wong T, Mitchell P. The eye in hypertension. Lancet. 2007;369(9559):42535.

18. Klein R, Deng Y, Klein BE, et al. Cardiovascular disease, its risk factors and treatment, and age-related macular degeneration: Women's Health Initiative Sight Exam ancillary study. Am J Ophthalmol. 2007;143(3):473-83.

19. Liew G, Kaushik S, Rochtchina E, Tan AG, Mitchell P, Wang JJ. Retinal vessel signs and 10-year incident age-related maculopathy: the Blue Mountains Eye Study. Ophthalmology. 2006;113(9):1481-7.

20. Klein R, Klein BE, Tomany SC, Wong TY. The relation of retinal microvascular characteristics to age-related eye disease: the Beaver Dam eye study. Am J Ophthalmol. 2004;137(3):435-44.

21. Ikram MK, van Leeuwen R, Vingerling JR, Hofman A, de Jong PTVM. Retinal vessel diameters and the risk of incident age-related macular disease: the Rotterdam Study. Ophthalmology. 2005;112(4):548-52.

22. Jeganathan VS, Kawasaki R, Wang JJ, et al. Retinal vascular caliber and age-related macular degeneration: the Singapore Malay Eye Study. Am J Ophthalmol. 2008;146(6):954-9.

23. Yang K, Zhan SY, Liang YB, et al. Association of dilated retinal arteriolar caliber with early age-related macular degeneration: the Handan Eye Study. Graefes Arch Clin Exp Ophthalmol. 2012;250(5):741-9.

24. Xu L, Wang S, Li Y, Jonas JB. Retinal vascular abnormalities and prevalence of agerelated macular degeneration in adult Chinese: the Beijing Eye Study. Am J Ophthalmol. 2006;142(4):688-9. 
25. Chin YC, Wong TY, Cheung CM, et al. Retinal Vascular Caliber and Age-related Macular Degeneration in an Indian Population from Singapore. Ophthalmic Epidemiol. 2014 Jun 19:1-6. [Epub ahead of print] PubMed PMID:24945891.

26. Klein R, Davis MD, Magli YL, Segal P, Klein BE, Hubbard L. The Wisconsin agerelated maculopathy grading system. Ophthalmology. 1991;98(7):1128-34.

27. Bird AC, Bressler NM, Bressler SB, et al. An international classification and grading system for age-related maculopathy and age-related macular degeneration. The International ARM Epidemiological Study Group. Surv Ophthalmol. 1995;39(5):36774.

28. Knudtson MD, Lee KE, Hubbard LD, Wong TY, Klein R, Klein BE. Revised formulas for summarizing retinal vessel diameters. Curr Eye Res. 2003;27(3):143-9.

29. Liew G, Sharrett AR, Kronmal R, et al. Measurement of retinal vascular caliber: issues and alternatives to using the arteriole to venule ratio. Invest Ophthalmol Vis Sci. 2007;48(1):52-7.

30. Wong TY, Mitchell P. The eye in hypertension. Lancet 2007; 369:425-35.

31. Klein $R$, Deng $Y$, Klein BE, et al. Cardiovascular disease, its risk factors and treatment, and age-related macular degeneration: Women's Health Initiative Sight Exam ancillary study. Am J Ophthalmol. 2007;143:473-83.

32. Klein R, Klein BE, Marino EK, et al. Early age-related maculopathy in the Cardiovascular Health Study. Ophthalmology 2003;110:25-33 
401 33. van Leeuwen R, Ikram MK, Vingerling JR, Witteman JC, Hofman A, de Jong PT. Blood pressure, atherosclerosis, and the incidence of age-related maculopathy: the Rotterdam Study. Invest Ophthalmol Vis Sci. 2003;44(9):3771-7.

404 34. Sherry LM, Wang JJ, Rochtchina E, et al. Reliability of computer-assisted retinal 405

35. Mitchell $\mathrm{P}$, Cheung $\mathrm{N}$, de Haseth $\mathrm{K}$, et al. Blood pressure and retinal arteriolar 407 narrowing in children. Hypertension. 2007;49(5):1156-62. 